\title{
Extractive Spectrophotometric Determination of Pd(II) with Sodium salt of hexamethyleneiminecarbodithioate
}

\author{
S. D. Dhanavate ${ }^{1}$, D. J. Garole ${ }^{2, *}$, V. J. Garole $^{3}$, S. R. Tetgure ${ }^{4}$, \\ A. D. Sawant ${ }^{1}$ \\ ${ }^{1}$ Inorganic Chemistry Division, The Institute of Science, 15, Madam Cama Road, \\ Mumbai - 400032, India \\ ${ }^{2}$ Dirctorate of Geology and Mining, Government of Maharashtra, Nagpur - 440010, India \\ ${ }^{3}$ Konkan Education Society's S .P. Jain Junior College, Nagothane, Taluka Roha, \\ District Raigad - 402106, India \\ ${ }^{4}$ School of Chemical Sciences, North Maharashtra University, Jalgaon - 425001, India \\ *E-mail address: drdipakgarole@gmail.com
}

\begin{abstract}
The reagent NaHMICdt $2 \mathrm{H}_{2} \mathrm{O}$ has found to be a good chelating agent for the spectrophotometric determination of various metal ions. The present investigation deals with spectrophotometric determination of $\mathrm{Pd}(\mathrm{II})$ by using $\mathrm{NaHMICdt} \cdot 2 \mathrm{H}_{2} \mathrm{O}$. The reagent reacted with $\mathrm{Pd}$ (II) to give yellow complex extractable into toluene. Pd (II) was extracted quantitatively in the $\mathrm{pH}$ range 0.5-2.0. Pd(II)-HMICdt complex showed $\lambda \max$ at $435 \mathrm{~nm}$. The extracted species has a 1:2 (M:L) stoicheometry. Beer's law is obeyed in the range of $0.2-0.8 \mu \mathrm{g} \mathrm{ml}^{-1}$ of Pd (II). The molar absorptivity and the sandells sensitivity were found to be $0.754 \times 10^{4} 1 \mathrm{~mol}^{-1} \mathrm{~cm}^{-1}$ and $0.0140 \mu \mathrm{g} \mathrm{mol}^{-1} \mathrm{~cm}^{-2}$ respectively. The effect of divers ion on the extraction of $\mathrm{Pd}(\mathrm{II})$ has been investigated. The proposed method is highly sensitive, selective, and simple and rapid has been applied for accurate determination of palladium in synthesis mixtures and real samples.
\end{abstract}

Keywords: Palladium; Sodium hexamethyleneiminecarbodithioate; Extractive Spectrophotometry; Synthetic mixture; Real Samples

\section{INTRODUCTION}

It is well known that precious metals which possess special physical and chemical properties are important materials and have been applied widely in industry and technology recently [1-5]. Palladium has extensive applications in various fields like catalysis, pharmaceuticals, petroleum, electronics, jewelers etc. Therefore, its separation and estimation at trace level is of significant importance. Especially, the demand amount of platinum group metals (PGMs) has increased a lot in industry. To satisfy these demands, new methods for 
their recovery from ores and spent materials have been prompted [6-8]. However, in consideration of the low natural abundance of the precious metals, traditional production methods, such as precipitation and reducing process methods, do not meet their tremendously increasing demand in industries and other spheres. Solvent extraction has been proved to be a very efficient and practicable approach for extraction and recovery of the precious metals leached from their low graded sources or spent catalysts $[9,10]$. Many of these techniques are either time consuming or require sophisticated and expensive instruments. Extractive spectrophotometric methods are simpler techniques and have been widely used for determination of palladium. Palladium forms intensely colored complexes with hydrazones, dyes, dithiocarbonates, oximes, and thio compounds.

Using this property a number of extractive spectrophotometric methods of palladium determination with various reagents such as di-2-pyridyl-methanone-2-(5-nitro)pyridyl hydrazine [11], pyridine-2-acetaldehyde salicyloyl hydrazine [12], di-2-pyridyl ketonebenzoyl hydrazine [13], Isonitroso benzoylacetone [4], o-butyldithiocarbonate [15], pyridoxal-4phenyl-3-thiosemicarbazone [16], Benzyloxy benzaldehyde thiosemicarbazone (BBTSC) [17], N-ethyl-3-carbazolecarbaxaledehydethiosemicarbazone [18] and $\alpha$-benzoin oxime (ABO) [19], N,N,N',N'-tetra(2-ethylhexyl) thiodiglycolamide (T(2EH)TDGA) [20].

However, the existing methods suffer from various limitations such as longer extraction periods[11-13], temperature control [15], narrow pH range [12-16,18], less stability [14], and interference from other metal ions $[11,15,19]$.

Moreover, in some methods $[13,14]$, the extraction is not quantitative. In the present method an analytical reagent hexamethyleneiminecarbodithioate was used for the extractive spectrophotometric determination of $\mathrm{Pd}(\mathrm{II})$. New analytical method can be employed for efficient determination of $\operatorname{Pd}(\mathrm{II})$ at $\mu \mathrm{g}$ level. The result of analysis obtained were employed with those obtained by known method with certify value of palladium. The proposed method is sensitive rapid and free from many limitations.

\section{EXPERIMENTAL}

\subsection{Apparatus}

All absorbance measurements were carried out on Bousch and Lomb spectronic 20 spectrophotometer. A digital elico $\mathrm{pH}$ meter (Model LI -120) with combined glass electrode was used to determine the $\mathrm{pH}$ of the solution. The stock solution of $\mathrm{Pd}(\mathrm{II})$ was prepared by dissolving calculated amount of palladium chloride in double distilled water containing $10 \mathrm{ml}$ of concentrated hydrochloric acid acid. The solution was diluted to $250 \mathrm{ml}$ with doubly distilled water and standardized [21].

The reactant hexamethyleneimine brought from Lancaster was used without further purification. The ligand sodium salt of hexamethyleneiminecarbodithioate dehydrate was prepared by method reported in the literature [22].

\subsection{Reagents}

Stock solution of the reagent $(0.15 \%)$ was prepared by dissolving $\mathrm{NaHMICdt} \cdot 2 \mathrm{H}_{2} \mathrm{O}$ $(0.15 \mathrm{~g})$ in ethanol. The $\mathrm{pH} 2.0$ was adjusted by using $\mathrm{HCl}$ and $\mathrm{NH}_{3}$ solution of order. Cation and anion were prepared by dissolving there AR grade salts in doubly distilled water with a few drops of suitable acid. Synthetic mixtures were prepared by using standard solution of Palladium and desired metal ions. Analytical grade chemicals were used unless otherwise stated. Doubly distilled water was used throughout the experimental work. 


\subsection{Recommended Procedure}

To an aliquot containing $50 \mu \mathrm{g} \mathrm{Pd}(\mathrm{II}), 1 \mathrm{ml}$ of $0.15 \%$ HMICdt in ethanol was added. The $\mathrm{pH}$ of solution was adjusted by required volume of Ammonia and $\mathrm{HCl}$. It was diluted to $10 \mathrm{ml}$ with distilled water and the complex was extracted with toluene $(10 \mathrm{ml})$ equilibrated mixture for $1 \mathrm{~min}$ organic extract was collected in $10 \mathrm{ml}$ standard volumetric flask and made up to the mark with fresh solvent and absorbance was measured at $435 \mathrm{~nm}$ against similarly prepared reagent blank. The amount of $\mathrm{Pd}(\mathrm{II})$ was detected from the standard calibration curve.

\section{RESULTS AND DISCUSSION}

\subsection{Absorption spectra}

The yellow colored complex shows absorbance maximum at $435 \mathrm{~nm}$ (Figure 1) where reagent has no significant absorbance. Hence all absorbance measurements were carried out at $435 \mathrm{~nm}$ against reagent blank.

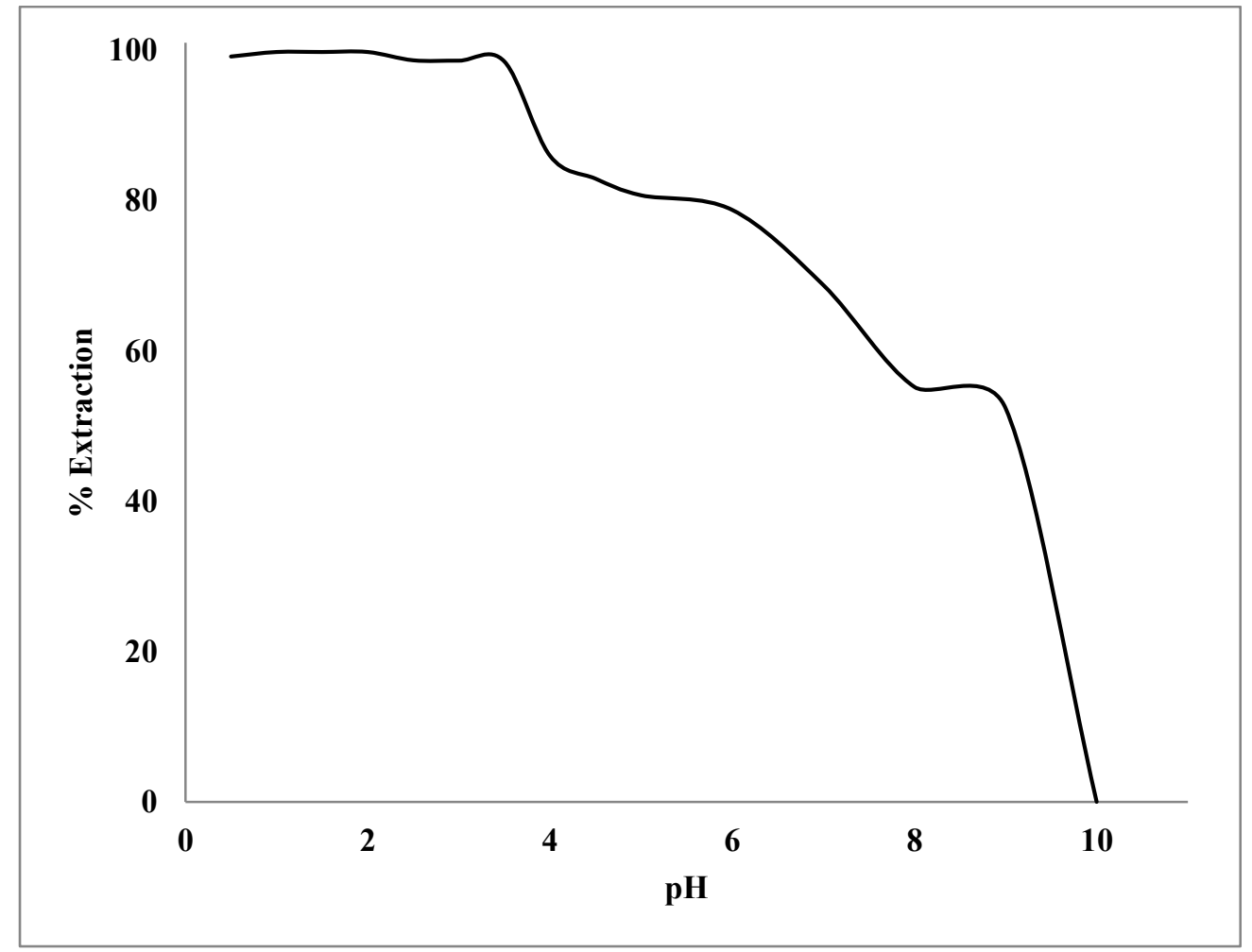

Fig. 1. Effect of $\mathrm{pH}$ on Extraction recovery of $\mathrm{Pd}(\mathrm{II})$

\subsection{Effect of pH and Acidity}

The extraction of Palladium as function of $\mathrm{pH} \mathrm{Pd}(\mathrm{II})$ was extracted by NaHMICdt $\cdot 2 \mathrm{H}_{2} \mathrm{O}$ in toluene over the $\mathrm{pH}$ range of 1-10 it was found that the complex would be quantitatively extracted in the $\mathrm{pH}$ range $0.5-2.0$, where the percentage extraction was found to be over $99.75 \%$ (Figure 2). 


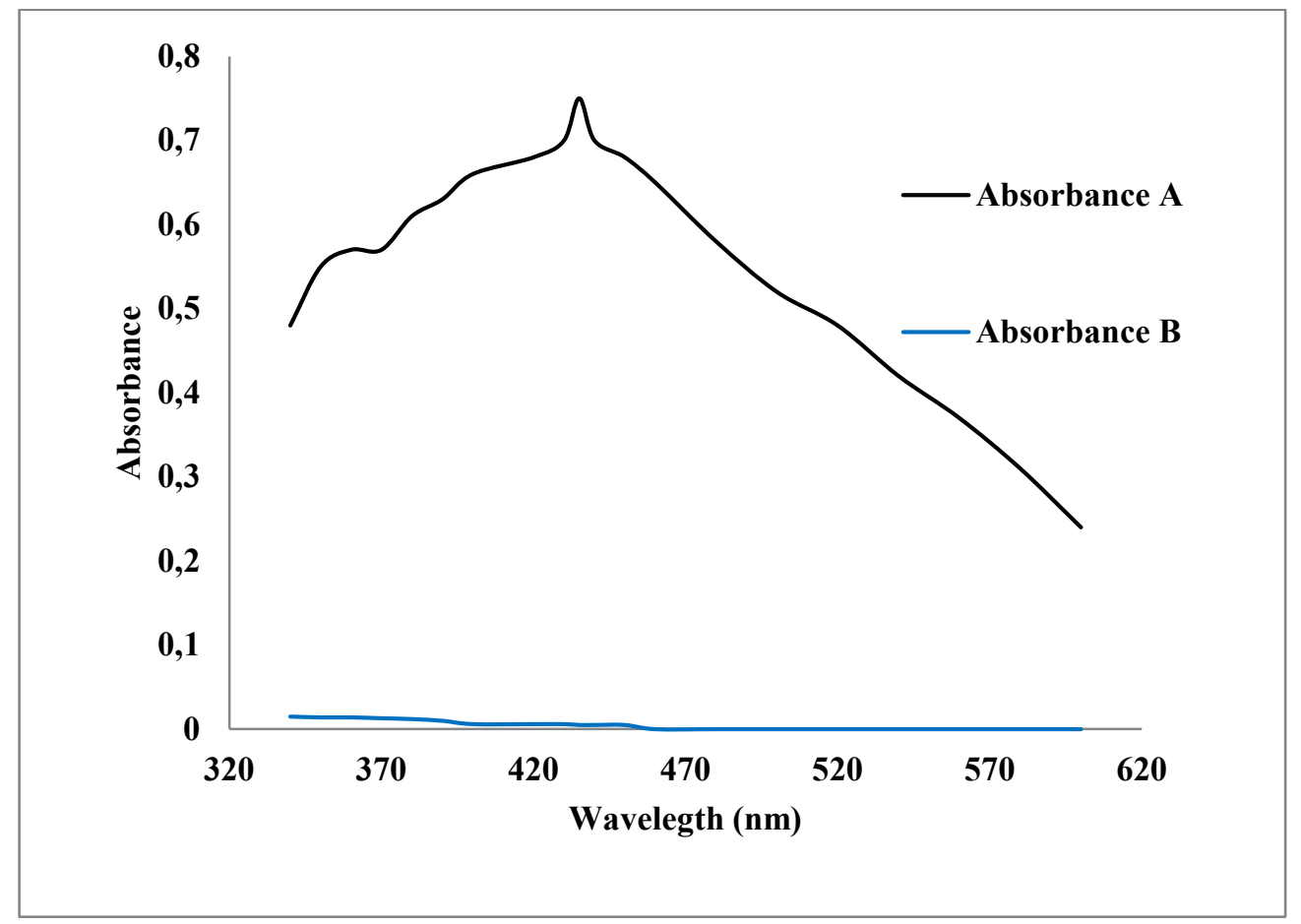

Fig. 2. Absorption spectra of Pd-HMIMcd complex (A) and reagent blank NaHIMCdt (B) in Toluene.

Therefore all extraction was carried out at $\mathrm{pH}$ 2.0. The extraction was also carried out in presence of various acid it was found that the extraction is quantitative in presence of $0.01 \mathrm{~N}$ $\mathrm{HCl}$ (Table 1).

Table 1. Recovery of $\mathrm{Pd}(\mathrm{II})$ in various acids

\begin{tabular}{|c|c|c|}
\hline & Acids & Extraction Recovery (\%) \\
\hline \hline 1 & $0.01 \mathrm{M} \mathrm{HCl}$ & 99.65 \\
\hline 2 & $0.1 \mathrm{M} \mathrm{HCl}$ & 83.55 \\
\hline 3 & $0.01 \mathrm{M} \mathrm{H}_{2} \mathrm{SO}_{4}$ & 86.65 \\
\hline 4 & $0.1 \mathrm{M} \mathrm{H}_{2} \mathrm{SO}_{4}$ & 71.11 \\
\hline 5 & $0.01 \mathrm{M} \mathrm{HNO}_{3}$ & 98.77 \\
\hline 6 & $0.1 \mathrm{M} \mathrm{HNO}_{3}$ & 68.77 \\
\hline 7 & $0.01 \mathrm{M} \mathrm{CH}_{3} \mathrm{COOH}_{3}$ & 97.67 \\
\hline 8 & $0.01 \mathrm{M} \mathrm{CH}_{3} \mathrm{COOH}$ & 80.69 \\
\hline
\end{tabular}




\subsection{Effect of Solvent}

Various organic solvents were tried to get maximum extraction of $\mathrm{Pd}(\mathrm{II})$ with HMICdt. The result shows that among various solvent, toluene was found to be the most suitable solvent for it quantitative extraction (Table 2).

Table 2. Recovery of Pd(II) in various solvents.

\begin{tabular}{|c|c|c|}
\hline & Solvent & Extraction Recovery (\%) \\
\hline 1 & Toluene & 99.75 \\
\hline 2 & Chloroform & 85.42 \\
\hline 3 & Benzene & 71.91 \\
\hline 4 & Iso- amyl alcohol & 69.00 \\
\hline 5 & Iso -butyl alcohol & 58.69 \\
\hline 6 & n-butyl alcohol & 49.20 \\
\hline 7 & Methyl isobutyl ketone & 38.40 \\
\hline 8 & Carbontetra Chloride & 16.66 \\
\hline 9 & n-butyl acetate & 15.96 \\
\hline 10 & Xylene & 14.23 \\
\hline 11 & Nitrobenzene & 12.26 \\
\hline 12 & Pentanol & 11.24 \\
\hline
\end{tabular}

\subsection{Effect of HMICdt. Concentration}

The effect of NaHMICdt $\cdot 2 \mathrm{H}_{2} \mathrm{O}$ concentration on extraction of $\mathrm{Pd}(\mathrm{II})$ was studied. It was observed that $1 \mathrm{ml}$ of $0.15 \%$ solution of $\mathrm{NaHMICdt} \cdot 2 \mathrm{H}_{2} \mathrm{O}$ was sufficient for quantitative extraction of $\mathrm{Pd}(\mathrm{II})$. Excess of reagent concentration did not affect on the extraction. Hence 1 $\mathrm{ml}$ of $0.15 \%$ reagent was used for further studies.

\subsection{Effect of Equilibration time}

The colour development was insisting, however shaking was varied from 10-120 second after reagent addition. The minimum shaking time required for quantitative extraction of $\operatorname{Pd}(\mathrm{II})$ was 60 second. While longer extraction time did not effect the $\%$ extraction. Hence 60 second of shaking time was fixed for further studies. 


\subsection{Colour Stability of the Extracted Species}

The color stability of Pd(II)-NaHMICdt complex was studied by measuring absorbance at $435 \mathrm{~nm}$ at definite time intervals. The complex was quantitative stable and remained constant for seven days.

\subsection{Calibration curve}

The absorbance of the extracted species was a linear function of $\mathrm{Pd}(\mathrm{II})$ concentration in the range of 0.2-8.0 ppm at $435 \mathrm{~nm}$. The optimum working range obtained from Ringbom's plot was found to be 1.778-7.24 ppm that confirms the beer's range (Figure 3). The molar absoptivity sandell's sensitivity of the method was found to be $0.754 \times 10^{4} \mathrm{~mol}^{-1} \cdot \mathrm{cm}^{-1}$ and $0.0140 \mu \mathrm{g} \cdot \mathrm{ml}^{-1} \cdot \mathrm{cm}^{-2}$ at $435 \mathrm{~nm}$ respectively.

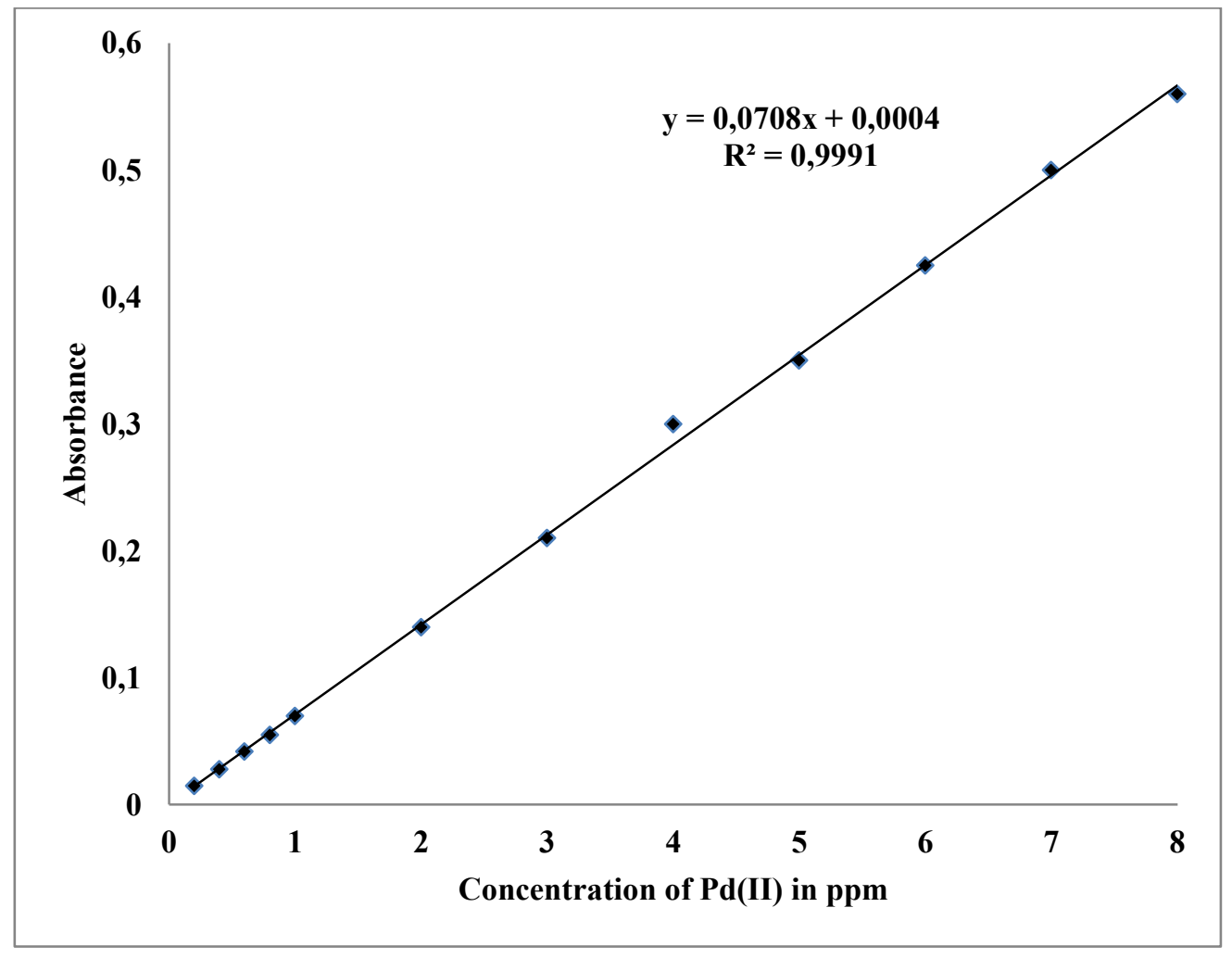

Fig. 3. Calibration Curve Pd(II).

\subsection{Effect of Foreign ions}

The tolerance level for the divers ions investigated were as follows $\mathrm{F}^{-}, \mathrm{Cl}^{-}, \mathrm{Br}^{-}, \mathrm{I}^{-}$, $\mathrm{NO}_{3}{ }^{-}, \mathrm{SO}_{4}{ }^{2-}, \mathrm{SO}_{3}{ }^{2-}, \mathrm{ClO}_{3}{ }^{-}, \mathrm{BrO}_{3}{ }^{-}, \mathrm{IO}_{3}{ }^{-}, \mathrm{S}_{2} \mathrm{O}_{8}{ }^{2-}, \mathrm{SCN}^{-}$, Acetate , Citrate, Tartarate, Oxalate, Urea ( 20 mg each). Li(I), $\mathrm{Na}(\mathrm{I}), \mathrm{K}(\mathrm{I}), \mathrm{Ca}(\mathrm{II}), \mathrm{Mg}(\mathrm{II}), \mathrm{Sr}(\mathrm{II}), \mathrm{Mo}(\mathrm{VI}), \mathrm{Sb}$ (III ), Ba(II), Cd(II), $\mathrm{Mn}(\mathrm{II}), \mathrm{Zn}(\mathrm{II}), \mathrm{Ni}(\mathrm{II}), \& \mathrm{Sb}(\mathrm{III})$ (10 mg each). Ti(III), V(IV),Pd(II), \& Hg(II) (5 mg each). Co (II) interferes and masked with EDTA. The tolerance limit was set as the amount of foreign ion that causes an error of not more than $+2 \%$ in the recovery of metal ion. 


\subsection{Precision and Accuracy}

The precision and accuracy of the method were determined the average of ten determination with $50 \mu \mathrm{g} \operatorname{Pd}(\mathrm{II})$ was found to be $49.931 \mu \mathrm{g}$ with standard deviation 0.3836 and the deviation from mean at $95 \%$ confident limit was \pm 0.1037 . The native of extraction complex was determined by job's continuous variation method and was found to be 1:2 (M:L) i.e Pd(II) - HMICdt was confirmed by mole ratio $1: 2$. The reaction is,

$$
\mathrm{Pd}(\mathrm{II})+\mathrm{NaHMICdt} \rightarrow \mathrm{Pd}(\mathrm{HMICdt})_{2}
$$

\subsection{Application}

\subsubsection{Synthetic mixture}

The developed method has been employed for estimation of Palladium in various synthetic mixture and real samples. A number of synthetic mixtures containing $50 \mu \mathrm{g}$ Palladium and other commonly associated metal ions were prepared by mixing there solution and analyzed according to developed method (Table 3).

Table 3. Determination of Pd(II) in various synthetic, Alloys Samples.

\begin{tabular}{|c|c|c|c|}
\hline Name of Sample & $\begin{array}{c}\text { Pd(II) Found by } \\
\text { Present Method }\end{array}$ & $\begin{array}{c}\text { Certified } \\
\text { Value }\end{array}$ & $\begin{array}{c}\text { Recovery } \\
\text { (\%) }\end{array}$ \\
\hline \hline Synthetic Mixture\# & & & \\
\hline $\mathrm{Pd}^{2+}(50 \mu \mathrm{g})+\mathrm{Co}^{2+}(50 \mu \mathrm{g})$ & 49.97 & 50 & 99.94 \\
\hline $\mathrm{Pd}^{2+}(50 \mu \mathrm{g})+\mathrm{Ni}^{2+}(100 \mu \mathrm{g})$ & 49.98 & 50 & 99.96 \\
\hline $\mathrm{Pd}^{2+}(50 \mu \mathrm{g})+\mathrm{Cu}^{2+}(50 \mu \mathrm{g})$ & 49.99 & 50 & 99.98 \\
\hline $\mathrm{Pd}^{2+}(50 \mu \mathrm{g})+\mathrm{Ag}^{1+}(100 \mu \mathrm{g})$ & 49.96 & 50 & 99.92 \\
\hline $\mathrm{Pd}^{2+}(50 \mu \mathrm{g})+\mathrm{Cd}^{2+}(100 \mu \mathrm{g})$ & 49.97 & 50 & 99.94 \\
\hline $\mathrm{Alloys} \mathrm{Samples}$ & & & \\
\hline $\mathrm{Pd}-\mathrm{Ag}$ Alloy\# & & & \\
\hline$(\mathrm{ITA} \mathrm{LAB})$ & 29.09 & 29.11 & 99.93 \\
\hline
\end{tabular}

\# Values are in $\mu \mathrm{g}, *$ Mean of Five determinations, ${ }^{\circledR}$ Values in percentage

\subsubsection{Analysis of alloys (White metal)}

The developed method has been employed for estimation of Palladium in various real samples like pd-Ag alloy. Definite amount of alloy was dissolved in concentrated nitric acid and solution was evaporating to dryness. The dried residue was taken up in dilute nitric acid. The solution was filtered off and washed with hot dilute nitric acid and finally washed with hot water then filtrate was collected and dilute to $100 \mathrm{ml}$ with distilled water. A definite aliquot of the above solution was used to extract and to determine palladium by developed method. The results obtained were compared with those of AAS (Table 3 ). 


\section{CONCLUSION}

The proposed method can be used for determination of Pd at trace level. Method has advantage of reliability, reproducibility, and good sensitivity, simple instant color development and minimum interference. The method has been successively applied foe the separation of Palladium at trace level in synthetic mixtures and real samples. The result obtained in the good agreement with the certify value and were compared with those obtained by known method.

\section{References}

[1] Singhal G., Bhavesh R., Kasariya K., Sharma A., Singh R., J Nanopart Res 13 (2011) 2981-2988.

[2] Cadete Santos Aires F. J., Kurzina I., Garcia Cervantes G., Bertolini J. C., Catal Today 117 (2006) 518-524.

[3] Moreno-Alvarez S. A., Martinez-Castanon G. A., Nino-Martinez N., Reyes-Macias J. F., Patino-Marin N., Loyola-Rodriguez J. P., Ruiz F., J Nanopart Res 12 (2010) 2741-2746.

[4] Iwase A., Kato H., Kudo A., Catal Lett. 108 (2006) 7-10.

[5] Nagy G., Hancsok J., Varga Z., Polczmann G., Kallo D., Top Catal. 45 (2007) 195-201.

[6] Chassary P., Vincent T., Marcano J. S., Macaskie L. E., Guibal E., Hydrometallurgy 76 (2005) 131-147.

[7] Barakat M. A., Mahmoud M. H. H., Hydrometallurgy 72 (2004) 179-184.

[8] Kramer J., Driessen W. L., Koch K. R., Reedijk J., Hydrometallurgy 64 (2002) 59-68.

[9] Rane M. V., Venugopal V., Hydrometallurgy 84 (2006) 54-59.

[10] Mhaske A. A., Dhadke P. M., Hydrometallurgy 61 (2001) 143-150.

[11] Kanetake T., Otomo M., Anal Sci. 4 (1988) 411-416.

[12] Sinha S. H., Sawant A. D., Bull Chem Soc Jpn. 65 (1992) 1622-1625.

[13] Nakanishi T., Otomo M., Anal Sci. 1 (1985) 161-164.

[14] Desai B. J., Shinde V. M., Fresenius Z Anal Chem. 295 (1979) 412-413.

[15] Kumar A., Gautam M., Puri B. K., Microchem. J. 33 (1986) 256-263.

[16] Sarma L. S., Kumar J. R., Reddy K. J., Kumar A. K., Reddy A. V., Anal Sci. 18 (2002) 1257-1261.

[17] Narayana S. L., Reddy K. J., Reddy S. A. N., Kumar J. R., Reddy A. V., J. Chin Chem Soc. 54 (2007) 1233-1241.

[18] Reddy K. J., Kumar J. R., Ramachandraiah C., Reddy A. V., Environ Monit Assess 136 (2008) 337-346.

[19] Dakshinamoorthy A., Singh R. K., Iyer R. H., J Radioanal Nucl Chem. 177 (1994) 3 27-333. 
[20] Ruhela R., Sharma J. N., Tomar B. S., Panja S., Tripathi S. C., Hubli R. C., Suri A. K., Radiochim Acta 98 (2010) 209-214.

[21] Jeffer G. H., Bassette J., Mendham J. A., Dennej R. C., Vogel Textbook of Quantitative Chemical Analysis, $5^{\text {th }}$ edn, English Language Book Society, England (1984).

[22] Singh A. K., Sharma S., Microchem J. 35 (1987) 365-368. 